Journal of

Women's Health and Gynecology

\title{
Premenstrual Syndrome- Prevalence, Severity and Effect on Academic Perfor- mance: A Comparative Study Between Students of Medicine and Literature
} Abeer Allihabi*

Department of Psychiatry, Taibah university, Saudi Arabia

${ }^{*}$ Corresponding author: Abeer Allihabi, Department of Psychiatry, Taibah university, Saudi Arabia

Received Date: May 27, 2019 Accepted Date: July 15, 2019 Published Date: July 17, 2019

Citation: Abeer Allihabi (2019) Premenstrual Syndrome- Prevalence, Severity and Effect on Academic Performance: A Comparative Study Between Students of Medicine and Literature. J Womens Health Gyn 6: 1-18.

\begin{abstract}
Premenstrual syndrome (PMS) is a common health problem in young women that affects their personal and professional lives. METHOD: This is a cross-sectional study, which was performed at Taibah University, Saudi Arabia, in 20152016.This study explores the determinants of PMS and its prevalence, severity and impact on students of medicine and literature respectively. RESULT: We find that medical students suffer less from PMS than literature students. The latter experience more severe symptoms and are highly affected in their routine chores, academic performance and self-care. CONCLUSION: Awareness and education about PMS and its risk factors should be considered for effective management of the syndrome and enhancement of the quality of daily life among Saudi women.
\end{abstract}

Keywords: Dysmenorrhea, menstruation, premenstrual syndrome, students 


\section{Introduction}

Premenstrual syndrome (PMS) refers to the emotional, behavioral and physical changes that occur in the late luteal phase of a woman's menstrual cycle (one to two weeks before her periods) $[1,2,3,4,5]$. It is usually observed in fertile women within the age group of 20-40, who may have a family history of PMS. Symptoms, which include acne, fatigue, tenderness of breasts or mastalgia, bloating, anxiety and mood fluctuations, usually last for six days and are resolved with the onset of menstruation, with a symptom-free interval afterwards [2]. The intensity of the symptoms varies among individuals and also between cycles in the same individual. Approximately $20-30 \%$ of premenopausal women exhibit PMS symptoms and 5-8\% suffer from extreme psychological disturbances that are classified as premenstrual dysphoric disorder (PMDD) under Diagnostic and Statistical Manual of mental disorders IV (DSM-IV) [4]. Pregnant and menopausal women do not undergo PMS [6].

While PMS is associated with 200 different symptoms, the underlying cause(s) remain unclear. It is believed that the trigger behind PMS is multifactorial in nature, with perturbations in reproductive hormone levels being one of the major causes [6]. Hormonal fluctuations differ among women, which explains the differences in the severity of the symptoms. Factors such as depression, stress, high consumption of caffeine or alcohol, high sodium levels, low levels of vitamins and minerals do not cause PMS but may exacerbate the symptoms [6]. Therefore, mild PMS can be controlled by reducing intake of caffeine, alcohol and sodium, supplementing diet with calcium and vitamin $\mathrm{D}$, managing stress and increasing hours of exercise $[6,7]$ whereas moderate PMS is treated with anti-inflammatory drugs, oral contraceptive pills and hormone therapy (use of gonadotropin releasing hormone agonists that target the hypothalamus-pituitary-ovary axis and estrogen). PMDD requires the administration of antidepressants such as selective serotonin uptake inhibitors on a regular or periodic basis [6].

There are no laboratory tests to diagnose PMS. Physicians ask women, who undergo certain degrees of physical and emotional discomfort in the late luteal phase of the menstrual cycle, to keep a record of the symptoms and their severity for at least two consecutive cycles. A woman who has at least one mood symptom and more than one physical symptom during her premenstrual or late luteal phase could be suffering from PMS. The criteria for DSM-V diagnosis requires a woman to have at least [5] out of [11] symptoms pertaining to PMDD.
Out of the five, one must be a mood symptom that takes into account depression, anxiety, difficulty in concentration, feeling overwhelmed and irritability [8]. Other symptoms include fatigue, changes in sleep pattern and appetite, decreased interest in daily activities, breast tenderness, abdominal cramps, bloating and headache [9]. It is necessary for these symptoms to be confined to the luteal phase of the cycle and their severity enough to cause psychosocial impairment. The DSM-V further states that the symptoms must be more than a mere exacerbation of other disorders that are magnified perimenstrually, a process called menstrual magnification [3]. Some of these conditions include migraine, seizures, depression, asthma or allergies, hypothyroidism, eating disorders and anemia [10]. The effect of these conditions must be excluded to make correct diagnosis of PMS. Similarly, problems of the female reproductive system such as endometriosis, dysmenorrhea, perimenopause and adverse effects of oral contraceptive medicines must be excluded.

Prospective and retrospective studies report the prevalence rates of PMS to be $4.6 \%$ and $6.7 \%$ respectively $[12,13]$. However, other studies mention that $20 \%$ or more women of childbearing age can experience PMS symptoms that are clinically relevant. There have also been studies that reported about "sub-threshold PMDD" and how it affected 18.6\%-20.7\% of women. The condition fails to fulfil the criteria as it shows less than the stipulated five symptoms and does not meet the functional impairment criterion $[14,15]$. Various menstrual dysfunction manifestations were measured with the help of a study involving female medical students of Thamar University, Yemen. Dysmenorrhea was present in close to three quarters of the cases and of which $14.2 \%$ experienced severe pain. The occurrence of self-reported PMS was $24.13 \%$. College absenteeism was reported in $36.2 \%$ cases and the average number of absent days was 2.1 \pm 0.9 days. Interestingly, $53.6 \%$ females with a negative attitude towards menstruation had PMS [16]. All students of Jinnah Medical \& Dental College, Karachi, who participated in a study to document PMS, reported some degree of at least one symptom. As per DSM-IV diagnostic criteria, prevalence of PMS was 59\% and the frequency of psychological symptoms was $67.5 \%$. There was no association between age and living conditions with the severity of symptoms [17]. In a study to assess life style parameters as potential risk factors for PMS among students of El-Minia University, Egypt, $80.2 \%$ of the participants who had severe PMS either had family history of PMS, physical inactivity, low BMI, excess caffeine intake, frequent consumption of fast food or were smokers [18]. A survey at a Nigerian university showed that the number of respondents meeting the criteria for PMDD were $6.1 \%$. A fairly significant percentage $(86.7 \%)$ of these cases, 
amounting to 65 , reported painful menstruation. Out of them, 21.5\%, 49.2\% and 29.3\% exhibited mild, moderate and severe pain respectively. There was no causal relationship between psychiatric morbidity or gynecological factors and PMDD [19]. In a survey conducted at Mekelle University of Ethiopia, 83.2\% participants had at least one PMS symptom; PMS prevalence was $37.0 \%$, class absenteeism was $28.3 \%$, exam absenteeism was $19.8 \%$, poor exam performance was $8.1 \%$ and PMS-related withdrawal from classes was $1.7 \%$ [20]. Another study in india where questionnaire given to student's girls of MBBS 1st, 2nd, and 3rd years to assess the Prevalence of PMS among medical students and its impact on their academic and social performance show $12 \%$ of individuals with PMS become absent in class and $32 \%$ avoid joining social functions [45].

A survey to investigate PMS severity, dysmenorrhea, and school performance of medical students of Ataturk University School of Medicine, Erzurum, Turkey revealed that $67 \%$ had dysmenorrhea, which had strong correlation with severe PMS [21]. Similarly, 67\% students of three medical colleges of Mangalore, India, suffered from PMS. Irritability was found to be a common emotional symptom and abdominal bloating the most prevalent somatic symptom. Outgoing habits and loss of concentration were the daily activities that were affected the most by PMS. Majority of the students managed their symptoms by taking painkillers. Among the emotional symptoms, the prevalence of depression, anxiety and irritability was found to be significantly higher in the overweight category as was the proportion of PMS in general [22].

A study in Saudi Arabia addresses the phenomenology of PMS in female medical students. Impairing of daily activities and onset of psychological distress symptoms were linked to severe PMS and the possible factors which predispose one towards PMS include age, rural residence, regular cycles, early menarche and positive family history. Severe premenstrual symptoms resulted in poor school performance [23]. Our study is the first comparative analysis of PMS prevalence, symptoms and severity between students of two different disciplines in Saudi Arabia. We report that, in general, medical students suffered less than students of literature during PMS. The reasons could be better awareness about PMS and fitter lifestyle adopted by medical students compared with students of literature.

\section{Methods}

This is a cross-sectional study, which was performed at Taibah University, Saudi Arabia, in 2015-2016. It included 150 students each from the departments of medicine and literature. Participants were asked to fill out the forms described below and provided 15 minutes to do so; they were advised not to identify themselves on the questionnaire, which was kept confidential. The study included only unmarried, nulliparous, and healthy female students from the first to the final year, belonging to the 18-25 age bracket. Voluntary participation was encouraged and written consent was taken before data collection.

The form consisted of three parts. The first part covered socio-demographic, lifestyle and reproductive data about the respondents such as age, weight, height, age of first menarche, length of menstrual cycle, duration of bleeding period, regularity of period, dietary habits, smoking habits, frequency of physical exercise and family history of dysmenorrhea. The second part covered criteria from the Diagnostic and Statistical Manual of mental disorders (DSM-V) to diagnose PMS. A self-report questionnaire developed by Halbreich et al, whose validity has been described, was used for the study. It is known as SFAF or Shortened Premenstrual Assessment Form. The form comprises 10 items that calculate changes in mood, behavior and symptoms of physical nature during the premenstrual period. The symptoms are categorized into three classes, describing affect, water retention and pain. A final score is measured on the basis of summation of positive responses to the symptoms. Symptom severity is evaluated on a 1-6 scale, keeping in mind changes from the state of non-premenstruation. Figures 1, 2, 3, 4, 5, and 6 relate to no, minimal, mild, moderate, severe and extreme change respectively. The third part of the questionnaire recorded impairment in physical and mental activities, for example, limited social activity, lack of self-care, reduced concentration in the class, poor school attendance and performance in examinations during premenstrual days. The Verbal Multidimensional Scoring System was utilized to measure the severity of dysmenorrheal: Grade 0 involves menstruation that is painless. Grade 1 deals with menstruation accompanied by pain but normal activity and very less use of analgesics. Grade 2 concerns moderate pain at the time of menstruation, a fair influence on daily activity and analgesic use for pain relief. Grade 3 has to do with severe pain during menstruation, considerable limitations to daily activity, headaches, diarrhea, nausea, tenderness, vomiting and no particular use of analgesics. Moderate to severe dysmenorrhea patients were included. Multiple regression method was used to model the data. This study has been reviewed and accepted for ethical compliance by Taibah University Research Ethical Committee 


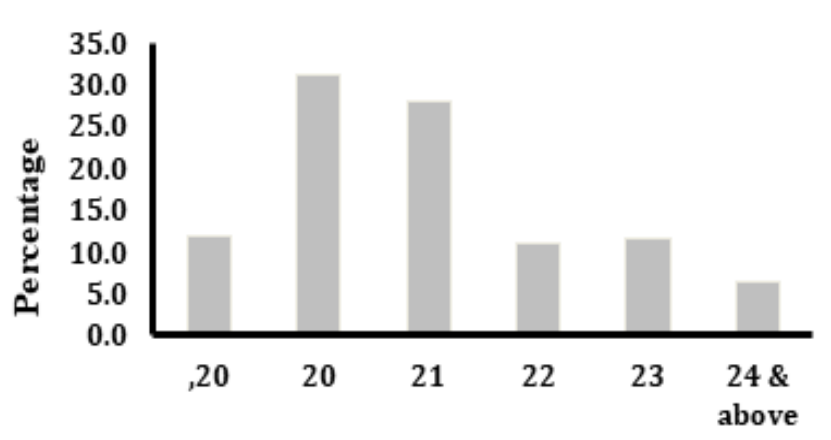

Age in year

Figure 1 A: Age distribution of study participants

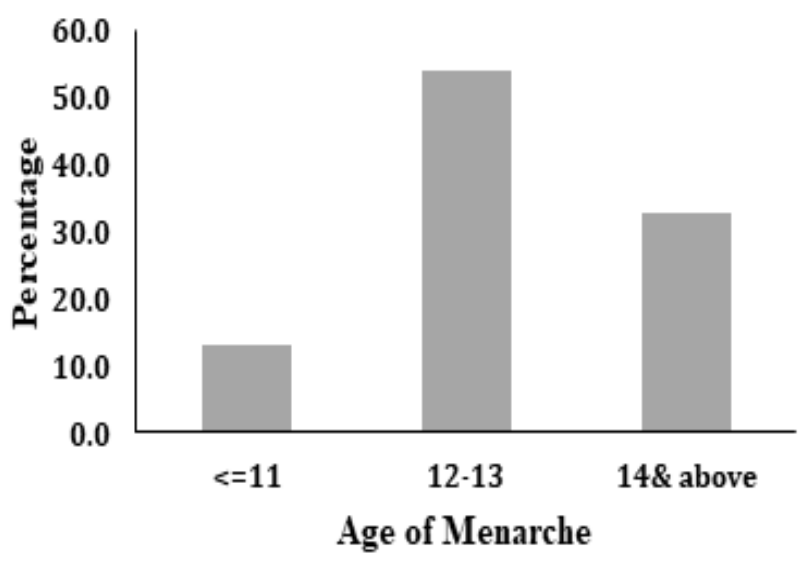

Figure 1 B: Distribution of age of menarche of study participants

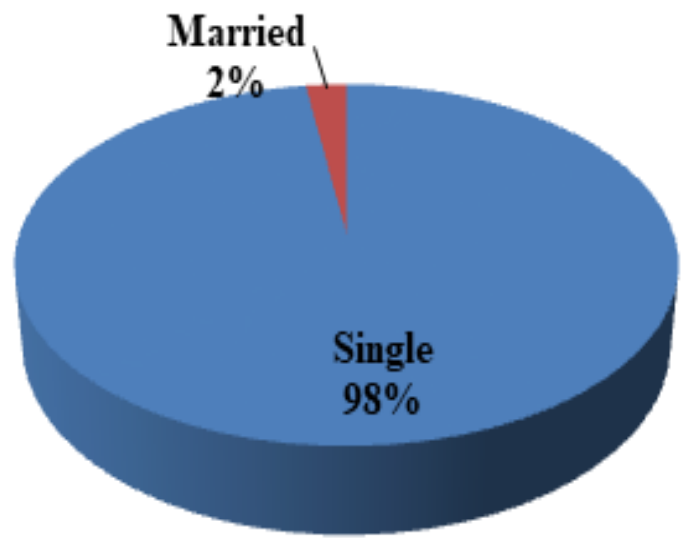

Figure 1C: Marital status of study participants

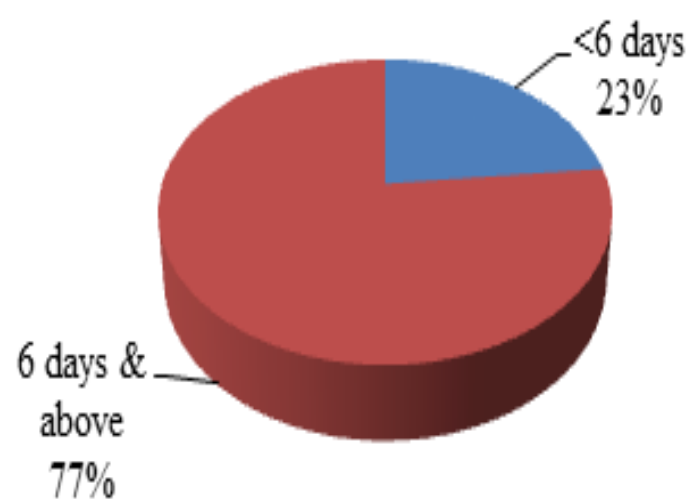

Figure 1D: Duration of menstrual cycle of study participants

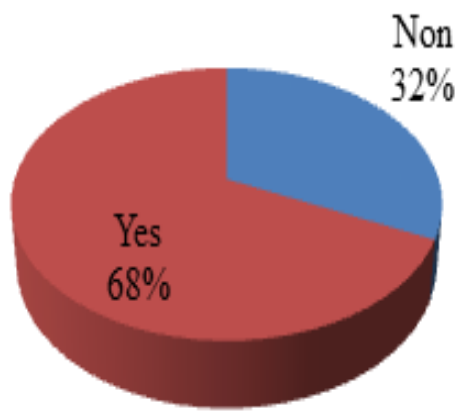

Figure 1E: Family history of PMS of study participants

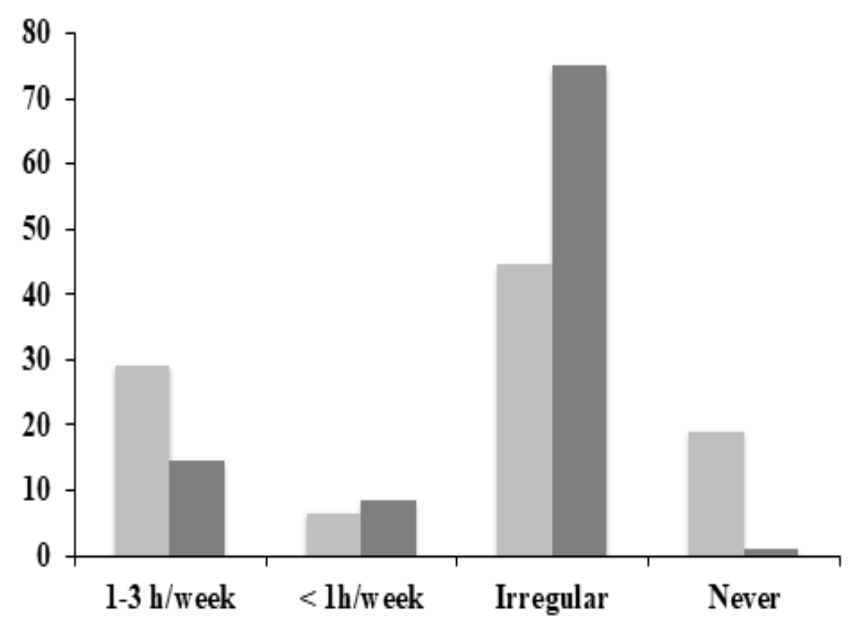

Figure 1F: Comparison of the amount of exercise ofmedical and literature students 


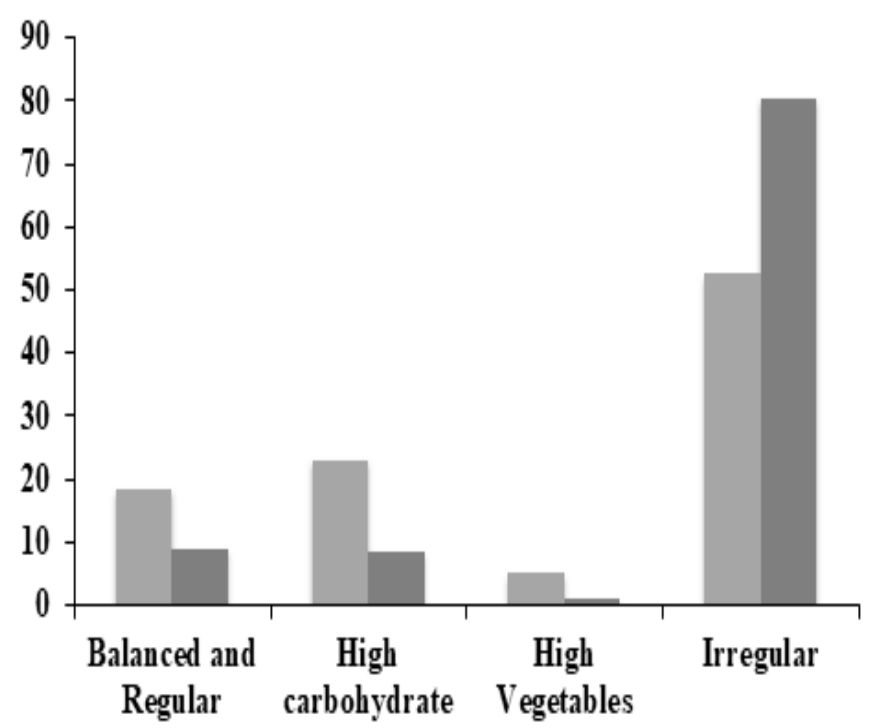

Figure 1G: Comparison of diets of medical and literature students

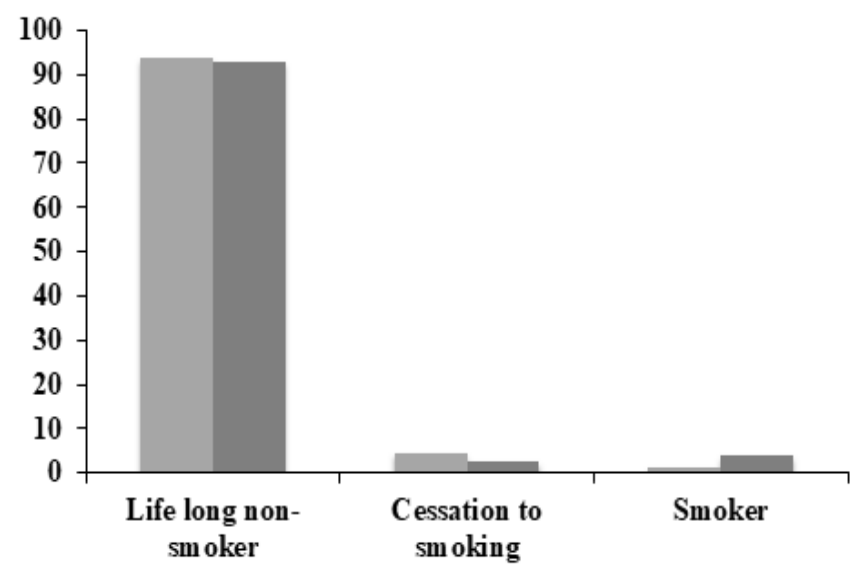

Figure 1H: Comparison of smoking habits of medical and literature students

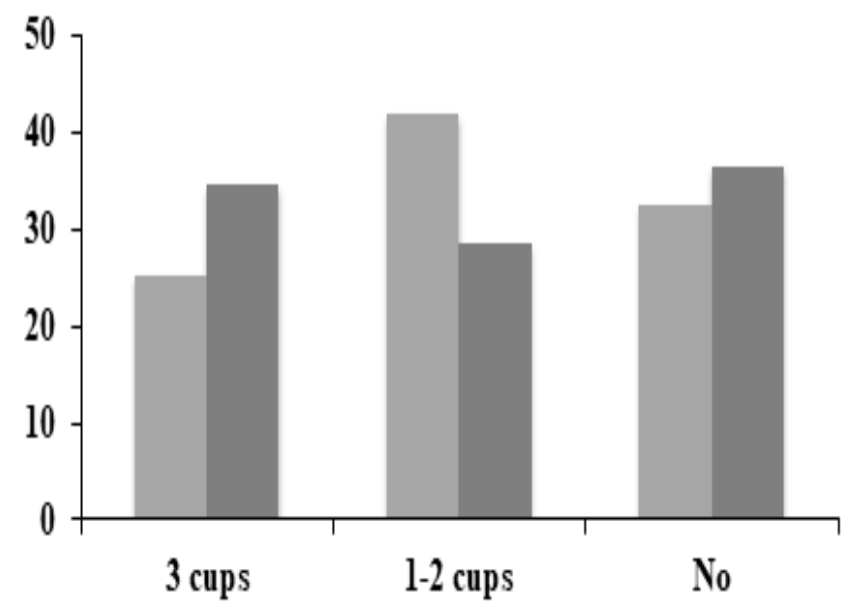

Figure 1I: Comparison of caffeine intake of medical and literature students

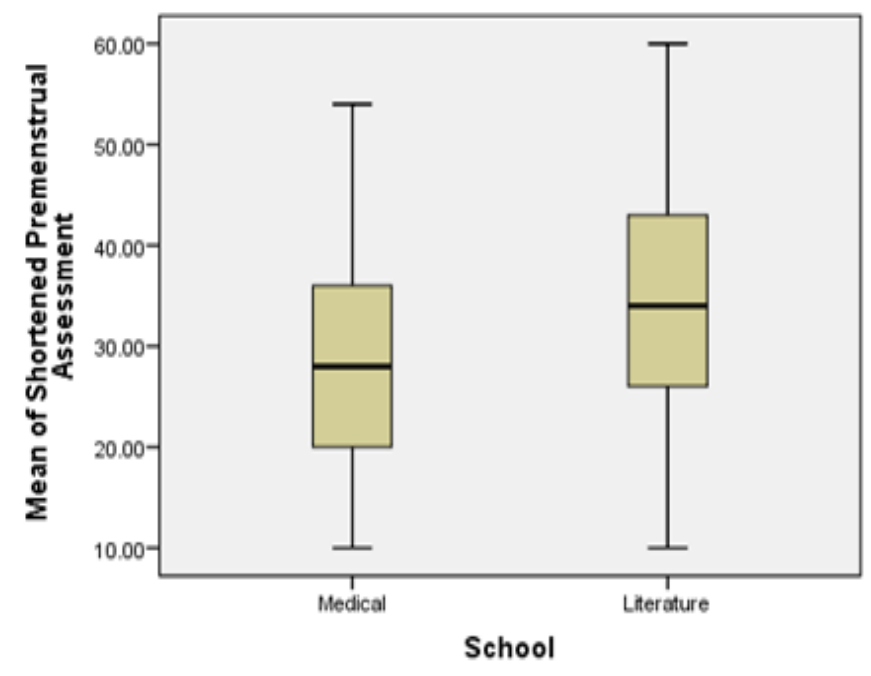

Figure 1J: Box plot depicting the mean of SPAF for school of participants

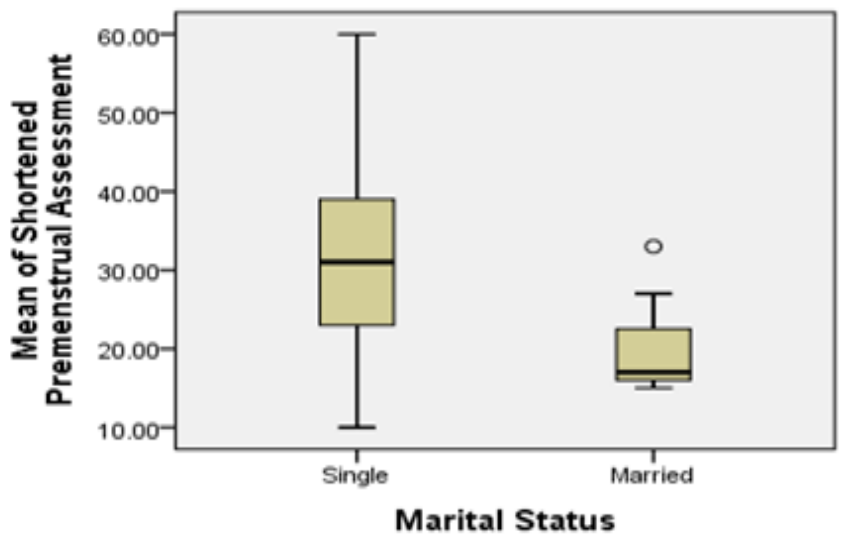

Figure 1K: Box plot depicting the mean of SPAF for marital status of participants

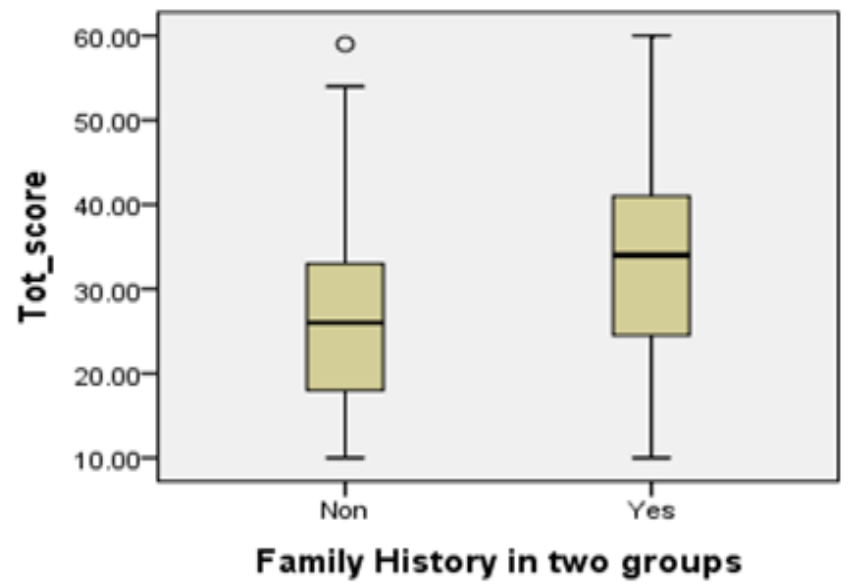

Figure 1L: Box plot depicting the mean of SPAF for family history of participants 


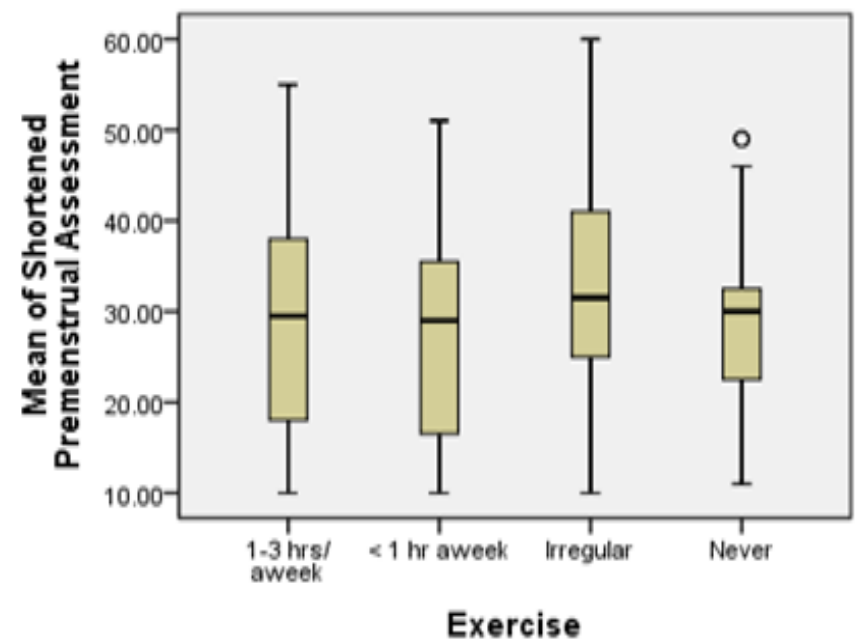

Figure 1M: Box plot depicting the mean of SPAF for amount of exercise

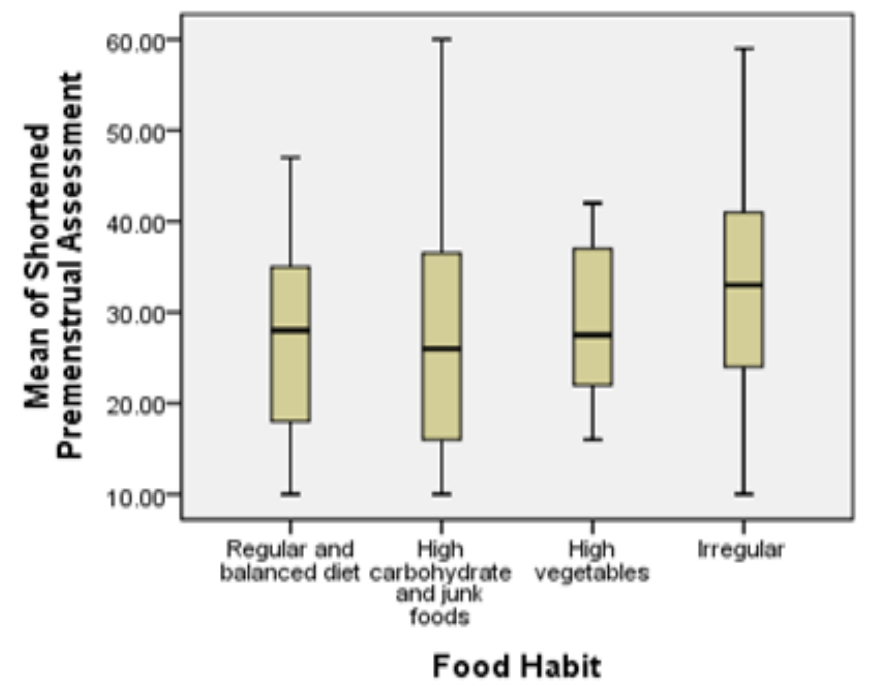

Figure 1N: Box plot depicting the mean of SPAF for diet

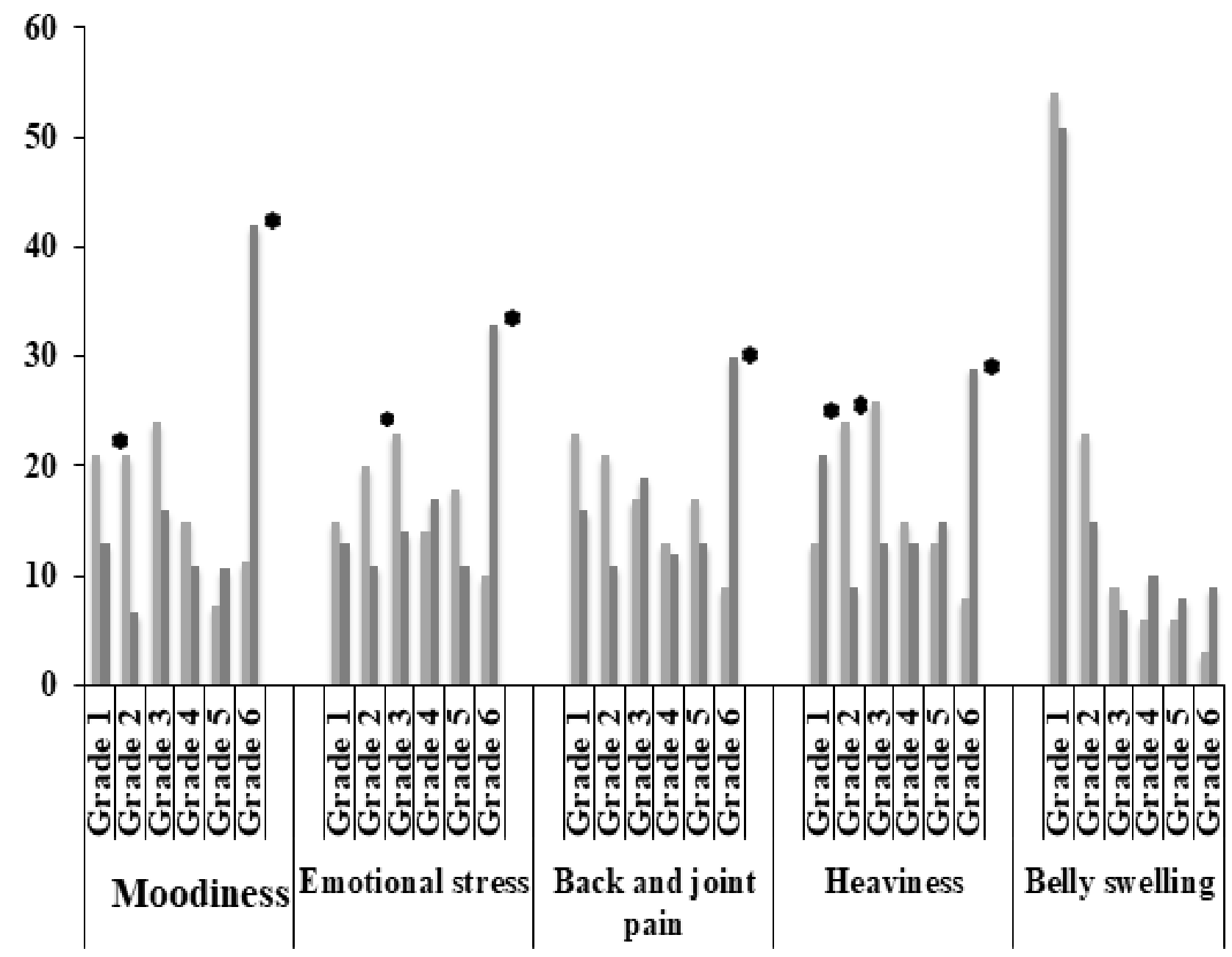

Figure 2: Evaluation of the severity of PMS symptoms in study participants 


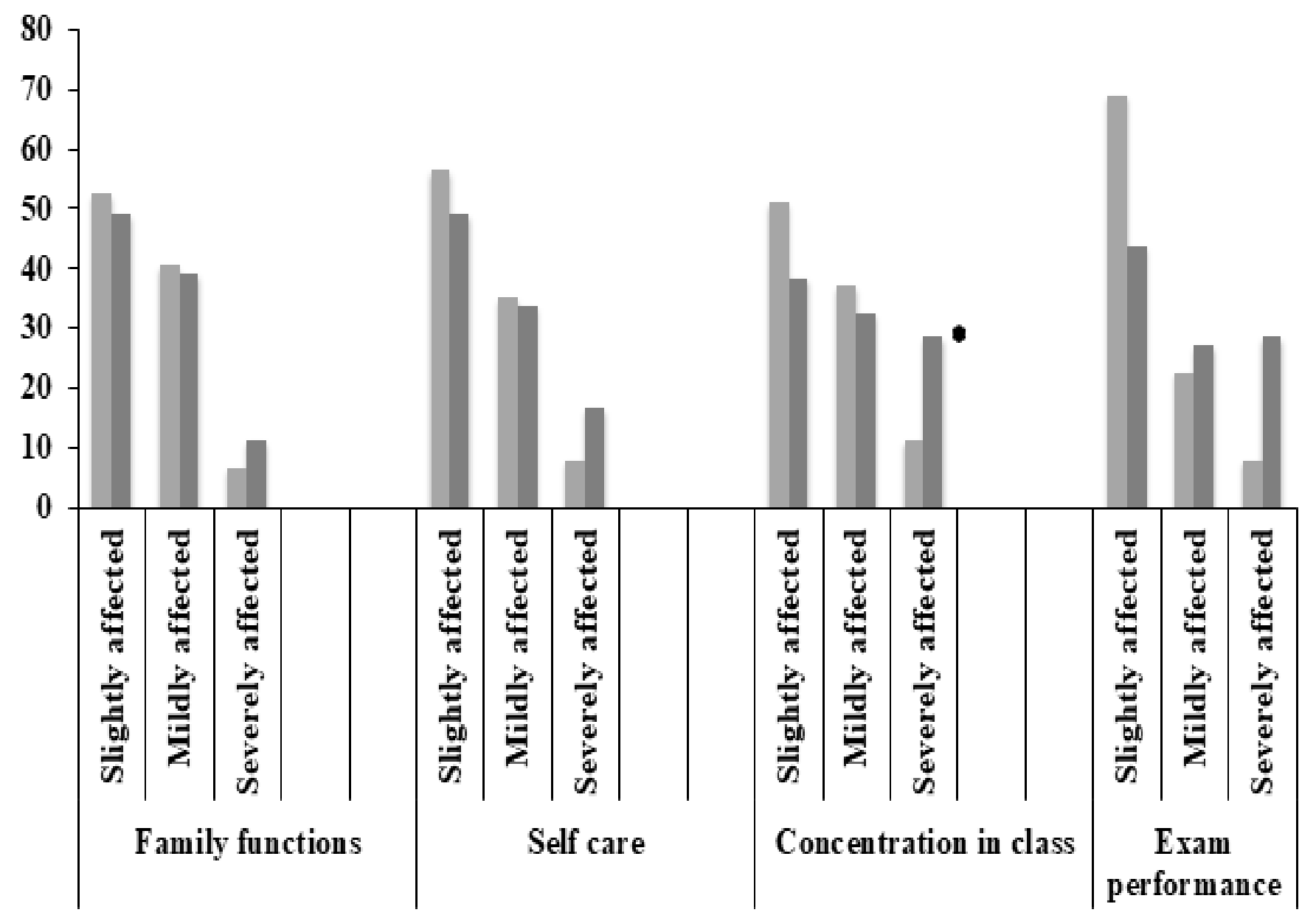

Figure 3: Effect of PMS severity on daily activities

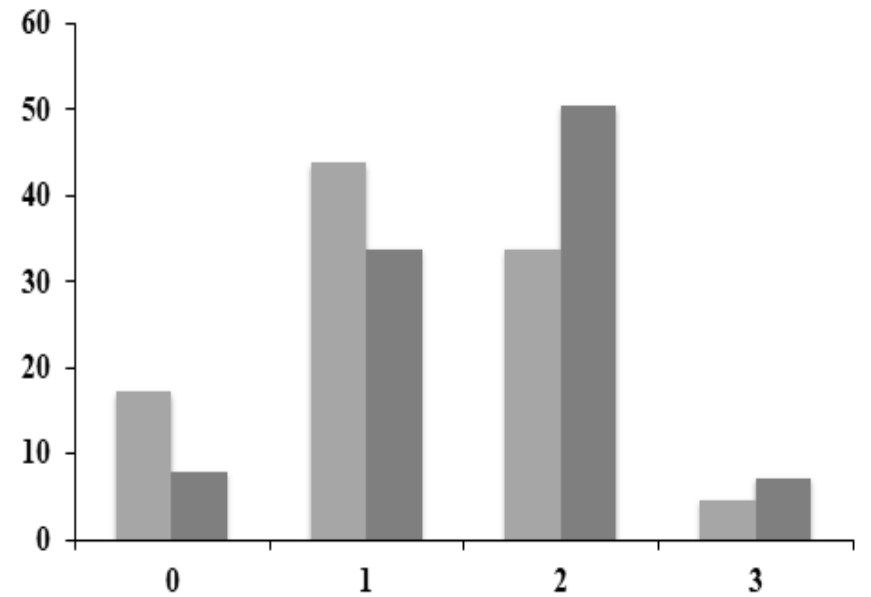

Figure 4A: Assessment of dysmenorrhea severity of the study participants

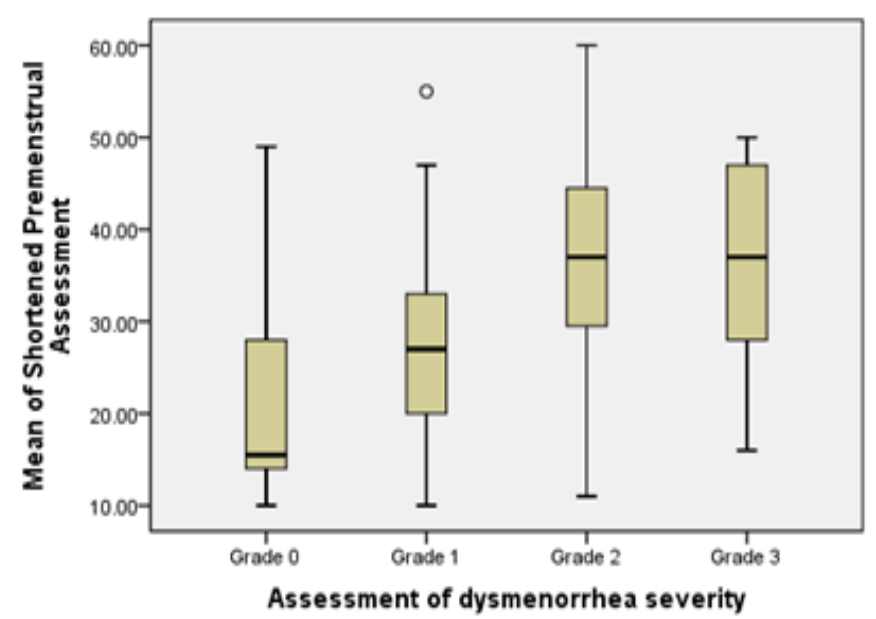

Figure 4B: Box plot depicting the mean of SPAF for dysmenorrhea severity 


\section{Results}

Effect of socio-demographic, reproductive and lifestyle characteristics on PMS: Previous studies have indicated that age, family history, life style factors such as consumption of coffee, smoking, amount of daily exercise, BMI, etc. affect the duration and severity of PMS $[1,6,7]$. Therefore, we analyzed whether certain socio-demographic, reproductive and lifestyle characteristics of our respondents influence the severity of their PMS symptoms. Table 1 lists these characteristics of the respondents from schools of medicine and literature respectively, and also the average data from both the schools. It is clear that the average age of the respondents in either school is 21 years (figure $1 \mathrm{~A}$ ) and 13 years is the average age of menarche (figure 1B). Majority of the respondents in both the schools are single (figure 1C), menstruate for six or more days (figure 1D) and have a preponderance of family history of PMS (figure 1E). However, incidence of family history of PMS is slightly higher (78\% for literature vs. $58 \%$ for medicine in table 1) in literature students than in students of medicine. Interestingly, the percentages of students who exercise 1-3 hours a week is double among students of medicine than in literature $(29.3 \%$ vs. $14.7 \%$ in table 1 , figure $1 \mathrm{~F})$. Also, the percentage that exercises irregularly is significantly higher in students of medicine, indicating that in general, medical students could be fitter than literature students (table 1, figure $1 F)$. The number of medical students with regular and healthy dietary habits is double of their literature counterparts (table 1, figure $1 \mathrm{G}$ ). The percentage reporting irregular meal consumption is also less in the medicine department. However, intake of high carbohydrate and junk food is more in medicine students than in literature students (figure 1G). Consumption of coffee and smoking habits is comparable between the two disciplines (figures $1 \mathrm{H}, 1 \mathrm{I}$ ). Upon integration of the socio-demographic, life-style and personal data with that of PMS severity (mild - 57 cases, moderate - 170 cases, severe - 73 cases), we found that the proportion of medical students who had severe PMS and PMS in general was lesser than those of literature students (table S1, figure 1J).The percentages that had mild to moderate PMS were comparable between the two (table S1). Also, married students suffered less during PMS (irrespective of discipline) than single ones (figure $1 \mathrm{~K}$ ). Age of menarche, duration of menstruation, body mass index (BMI) levels do not influence the severity of PMS (table S1), whereas a positive family history of PMS definitely increased the percentage suffering specifically from mild PMS (table S1) as well as PMS in general (figure 1L). Regularity of exercise does not significantly affect the severity of PMS, as we could not perceive any trend between severity of symptoms and hours of exercise (figure 1M). On the other hand, diet does moderately influence the intensity of PMS discomfort; diet high in vegetable content coincided with moderate PMS, and irregular meal consumption or intake of high carbohydrate value food overlapped with severe symptoms among the respondents (table S1).However, there is no clear trend linking diet type to PMS severity in the average population as depicted in figure $1 \mathrm{~N}$. Caffeine consumption and smoking do not seem to affect the acuteness of symptoms. However, the percentage of respondents with moderate symptoms shows a dramatic increase compared with mild symptoms $(0.0 \%$ vs.72.7\%) in the smoking cessation category (table S1). Qualitative assessment of the severity of PMS symptoms by premenstrual assessment form: We used a premenstrual assessment form (PAF) to gauge the intensities of various PMS-related symptoms in our respondents from the medicine and literature departments (table 2). Same parameters, but on non-premenstrual days were used for comparison. The severity of the parameters or symptoms was graded on a scale of 1 to 6 , where 1 represents no change and 6 extreme change. The data presented in table 2 clearly shows that students of literature suffer more from extreme changes in all the categories when compared with medical students (grade 6). The percentages in grades 1-5 are comparable between the two disciplines (table 2). Marked differences are seen in levels of moodiness, emotional stress, back and joint pain, heaviness and belly swelling (figure 2).

We then assessed the effect of PMS on daily activities such as self-care, family duties, performance in class and examinations (table 3). We observe that students of literature are most seriously affected in all the daily activities than medical students, whereas the percentages in the unaffected and mildly affected categories are comparable (table 3 and figure 3 ).

Assessment of dysmenorrhea severity among study participants: To estimate dysmenorrhea severity, the verbal multidimensional scoring system was used by us across the study participants. Dysmenorrhea is a collection of symptoms (abdominal pain, cramps) that a woman experiences one to two days before her menstruation and that is resolved with the onset of periods. Though PMS and dysmenorrhea occur at different time points in the menstrual cycle, we wanted to investigate whether there is any overlap between the participants who reported moderate to severe PMS and dysmenorrhea. Table 4 enlists the responses from students of medicine and literature, where grade 0 means no pain and grade 3 refers to extreme pain. The percentage of medical students who had painless dysmenorrhea is double than that of the literature department ( $17.3 \%$ vs. $8 \%$, table 4 , figure $4 \mathrm{~A})$. 


\begin{tabular}{|c|c|c|c|c|c|c|c|}
\hline \multirow{3}{*}{\multicolumn{2}{|c|}{ Data type }} & \multicolumn{4}{|c|}{ School } & \multirow{2}{*}{\multicolumn{2}{|c|}{ Total $(n=300)$}} \\
\hline & & \multicolumn{2}{|c|}{$\operatorname{Medical}(\mathrm{n}=150)$} & \multicolumn{2}{|c|}{ Literature $(n=150)$} & & \\
\hline & & No & $\%$ & No & $\%$ & No & $\%$ \\
\hline \multicolumn{8}{|c|}{$\begin{array}{l}\text { Socio demographic data } \\
\text { Age in years }\end{array}$} \\
\hline & $<20$ & 12 & 8.0 & 24 & 16.0 & 36 & 12.0 \\
\hline & 20 & 55 & 36.7 & 38 & 25.3 & 93 & 31.0 \\
\hline & 21 & 42 & 28.0 & 42 & 28.0 & 84 & 28.0 \\
\hline & 22 & 11 & 7.3 & 22 & 14.7 & 33 & 11.0 \\
\hline & 23 & 19 & 12.7 & 16 & 10.7 & 35 & 11.7 \\
\hline & $24 \&$ above & 11 & 7.3 & 8 & 5.3 & 19 & 6.3 \\
\hline & Mean \pm SD & \multicolumn{2}{|l|}{$21.1 \pm 1.9$} & \multicolumn{2}{|c|}{$21.0 \pm 1.5$} & \multicolumn{2}{|c|}{$21.5 \pm 1.7$} \\
\hline & Median & \multicolumn{2}{|l|}{21} & \multicolumn{2}{|c|}{21} & \multicolumn{2}{|c|}{21} \\
\hline & Min/Max & \multicolumn{2}{|l|}{$19 / 35$} & \multicolumn{2}{|c|}{$18 / 26$} & \multicolumn{2}{|c|}{$18 / 35$} \\
\hline \multicolumn{8}{|c|}{ Age of Menarche } \\
\hline & $<=11$ & 24 & 16.0 & 15 & 10.0 & 39 & 13.0 \\
\hline & $12-13$ & 83 & 55.3 & 79 & 52.7 & 162 & 54.0 \\
\hline & $14 \&$ above & 43 & & 56 & 37.3 & 99 & 33.0 \\
\hline & Mean \pm SD & $12.8 \pm 1.8$ & 28.7 & \multicolumn{2}{|c|}{$13.0 \pm 1.6$} & \multicolumn{2}{|c|}{$12.9 \pm 1.7$} \\
\hline & Median & \multicolumn{2}{|l|}{13} & 13 & & 13 & \\
\hline & Min/Max & \multicolumn{2}{|l|}{$7 / 22$} & \multicolumn{2}{|c|}{$7 / 17$} & \multicolumn{2}{|l|}{$7 / 22$} \\
\hline \multicolumn{8}{|c|}{ Marital Status } \\
\hline & Single & 146 & 97.3 & 147 & 98.0 & 293 & 97.7 \\
\hline & Married & 4 & 2.7 & 3 & 2.0 & 7 & 2.3 \\
\hline \multicolumn{8}{|c|}{ BMI $(n=229)$} \\
\hline & $<18.5$ & 15 & 12.5 & 14 & 12.8 & 29 & 12.7 \\
\hline & $18.5-24.9$ & 71 & 59.2 & 57 & 52.3 & 128 & 55.9 \\
\hline & $25-<30$ & 23 & 19.2 & 10 & 9.2 & 33 & 14.4 \\
\hline & 30\& Above & 11 & 9.2 & 28 & 25.7 & 39 & 17.0 \\
\hline \multicolumn{8}{|c|}{$\begin{array}{l}\text { Reproductive data } \\
\text { Duration of menstruation }\end{array}$} \\
\hline & $<6$ days & 36 & 24.0 & 34 & 22.7 & 70 & 23.3 \\
\hline & 6 days $\&$ above & 114 & 76.0 & 116 & 77.3 & 230 & 76.7 \\
\hline \multicolumn{8}{|c|}{ Family history of PMS } \\
\hline & No & 63 & 42.0 & 33 & 22.0 & 96 & 32.0 \\
\hline & Yes & 87 & 58.0 & 117 & 78.0 & 204 & 68.0 \\
\hline
\end{tabular}

\begin{tabular}{|l|l|l|l|l|l|l|l|}
\hline \multicolumn{2}{|l|}{ Family historybreak-up } & & & & & & \\
\hline & No & 63 & $\mathbf{4 2 . 0}$ & 33 & $\mathbf{2 2 . 0}$ & 96 & $\mathbf{3 2 . 0}$ \\
\hline & Mother & 25 & $\mathbf{1 6 . 7}$ & 41 & $\mathbf{2 7 . 3}$ & 66 & $\mathbf{2 2 . 0}$ \\
\hline & Sister & 50 & $\mathbf{3 3 . 3}$ & 49 & $\mathbf{3 2 . 7}$ & 99 & $\mathbf{3 3 . 0}$ \\
\hline & Aunt & 5 & $\mathbf{3 . 3}$ & 12 & $\mathbf{8 . 0}$ & 17 & $\mathbf{5 . 7}$ \\
\hline & Cousin & 6 & $\mathbf{4 . 0}$ & 6 & $\mathbf{4 . 0}$ & 12 & $\mathbf{4 . 0}$ \\
\hline
\end{tabular}




\begin{tabular}{|c|c|c|c|c|c|c|c|}
\hline & Others & 1 & 0.7 & 9 & 6.0 & 10 & 3.3 \\
\hline \multicolumn{8}{|l|}{$\begin{array}{l}\text { Life style data } \\
\text { Exercise }\end{array}$} \\
\hline & 1-3 hrs/ a week & 44 & 29.3 & 22 & 14.7 & 66 & 22.0 \\
\hline & $<1$ hr a week & 10 & 6.7 & 13 & 8.7 & 23 & 7.7 \\
\hline & Irregular & 67 & 44.7 & 113 & 75.3 & 180 & 60.0 \\
\hline & Never & 29 & 19.3 & 2 & 1.3 & 31 & 10.3 \\
\hline \multicolumn{8}{|l|}{ Food Habit } \\
\hline & Regular and balanced diet & 28 & 18.7 & 14 & 9.3 & 42 & 14.0 \\
\hline & $\begin{array}{l}\text { High carbohydrate and junk } \\
\text { foods }\end{array}$ & 35 & 23.3 & 13 & 8.7 & 48 & 16.0 \\
\hline & High vegetables & 8 & 5.3 & 2 & 1.3 & 10 & 3.3 \\
\hline & Irregular & 79 & 52.7 & 121 & 80.7 & 200 & 66.7 \\
\hline \multicolumn{8}{|l|}{ Smoking } \\
\hline & Life long non-smoker & 141 & 94.0 & 140 & 93.3 & 281 & 93.7 \\
\hline & Cessation to smoking & 7 & 4.7 & 4 & 2.7 & 11 & 3.7 \\
\hline & Smoker & 2 & 1.3 & 6 & 4.0 & 8 & 2.7 \\
\hline \multicolumn{8}{|l|}{ Caffeine } \\
\hline & 3 cups or more & 38 & 25.3 & 52 & 34.7 & 90 & 30.0 \\
\hline & $1-2$ cups & 63 & 42.0 & 43 & 28.7 & 106 & 35.3 \\
\hline & No & 49 & 32.7 & 55 & 36.7 & 104 & 34.7 \\
\hline
\end{tabular}

Table 1: Socio-demographic, reproductive and life style characteristics of study participants

\begin{tabular}{|c|c|c|c|c|c|c|c|c|c|}
\hline \multirow[t]{3}{*}{ Data type } & \multirow[t]{3}{*}{ No. } & \multicolumn{6}{|c|}{ Shortened Premenstrual Assessment } & \multirow[t]{3}{*}{ Chi square } & \multirow[t]{3}{*}{ P-value } \\
\hline & & \multicolumn{2}{|c|}{ Mild (57) } & \multicolumn{2}{|c|}{ Moderate (170) } & \multicolumn{2}{|c|}{ Severe (73) } & & \\
\hline & & No & $\%$ & No & $\%$ & No & $\%$ & & \\
\hline \multicolumn{10}{|l|}{ School } \\
\hline Medical & 150 & 35 & 23.3 & 91 & 60.7 & 24 & 16.0 & 12.374 & 0.002 \\
\hline Literature & 150 & 22 & 14.7 & 79 & 52.7 & 49 & 32.7 & & \\
\hline \multicolumn{10}{|l|}{ Marital Status } \\
\hline Single & 293 & 52 & 17.7 & 168 & 57.3 & 73 & 24.9 & 13.111 & 0.001 \\
\hline Married & 7 & 5 & 71.4 & 2 & 28.6 & 0 & 0.0 & & \\
\hline \multicolumn{10}{|l|}{ BMI } \\
\hline$<18.5$ & 29 & 5 & 17.2 & 17 & 58.6 & 7 & 24.1 & 2.418 & 0.878 \\
\hline $18.5-24.9$ & 128 & 29 & 22.7 & 68 & 53.1 & 31 & 24.2 & & \\
\hline $25-<30$ & 33 & 6 & 18.2 & 20 & 60.6 & 7 & 21.2 & & \\
\hline 30\& Above & 39 & 5 & 12.8 & 23 & 59.0 & 11 & 28.2 & & \\
\hline \multicolumn{10}{|c|}{ Age of Menarche } \\
\hline$<=11$ & 39 & 9 & 23.1 & 21 & 53.8 & 9 & 23.1 & 2.561 & 0.634 \\
\hline
\end{tabular}




\begin{tabular}{|c|c|c|c|c|c|c|c|c|c|}
\hline $12-13$ & 162 & 28 & 17.3 & 98 & 60.5 & 36 & 22.2 & & \\
\hline 14\& above & 99 & 20 & 20.2 & 51 & 51.5 & 28 & 28.3 & & \\
\hline \multicolumn{10}{|l|}{ Duration of the menstruation } \\
\hline$<6$ days & 70 & 13 & 18.6 & 40 & 57.1 & 17 & 24.3 & 0.013 & 0.994 \\
\hline 6 days $\&$ above & 230 & 44 & 19.1 & 130 & 56.5 & 56 & 24.3 & & \\
\hline \multicolumn{10}{|l|}{ Family History } \\
\hline Non & 96 & 26 & 27.1 & 57 & 59.4 & 13 & 13.5 & 11.794 & 0.003 \\
\hline Yes & 204 & 31 & 15.2 & 113 & 55.4 & 60 & 29.4 & & \\
\hline \multicolumn{10}{|l|}{ Exercise } \\
\hline 1-3 hrs/ a week & 66 & 19 & 28.8 & 35 & 53.0 & 12 & 18.2 & 14.493 & 0.035 \\
\hline$<1 \mathrm{hr}$ a week & 23 & 7 & 30.4 & 13 & 56.5 & 3 & 13.0 & & \\
\hline Irregular & 180 & 25 & 13.9 & 101 & 56.1 & 54 & 30.0 & & \\
\hline Never & 31 & 6 & 19.4 & 21 & 67.7 & 4 & 12.9 & & \\
\hline \multicolumn{10}{|l|}{ Food Habit } \\
\hline Regular and balanced diet & 42 & 12 & 28.6 & 26 & 61.9 & 4 & 9.5 & 14.146 & 0.001 \\
\hline $\begin{array}{l}\text { High carbohydrate and junk } \\
\text { foods }\end{array}$ & 48 & 13 & 27.1 & 26 & 54.2 & 9 & 18.8 & & \\
\hline High vegetables & 10 & 1 & 10.0 & 8 & 80.0 & 1 & 10.0 & & \\
\hline Irregular & 200 & 31 & 15.5 & 110 & 55.0 & 59 & 29.5 & & \\
\hline \multicolumn{10}{|l|}{ Smoking } \\
\hline Lifelong non-smoker & 281 & 56 & 19.9 & 157 & 55.9 & 68 & 24.2 & 3.018 & 0.395 \\
\hline Cessation to smoking & 11 & 0 & 0.0 & 8 & 72.7 & 3 & 27.3 & & \\
\hline Smoker & 8 & 1 & 12.5 & 5 & 62.5 & 2 & 25.0 & & \\
\hline \multicolumn{10}{|l|}{ Caffeine } \\
\hline 3 cups or more & 90 & 21 & 23.3 & 45 & 50.0 & 24 & 26.7 & 3.167 & 0.530 \\
\hline $1-2$ cups & 106 & 16 & 15.1 & 65 & 61.3 & 25 & 23.6 & & \\
\hline None & 104 & 20 & 19.2 & 60 & 57.7 & 24 & 23.1 & & \\
\hline
\end{tabular}

Table S1: SPAF of socio-demographic data of study participants 


\begin{tabular}{|c|c|c|c|c|c|c|c|}
\hline \multirow{3}{*}{\multicolumn{2}{|c|}{ Symptoms }} & \multicolumn{4}{|c|}{ School } & \multirow{2}{*}{\multicolumn{2}{|c|}{ Total $(n=300)$}} \\
\hline & & \multicolumn{2}{|c|}{$\operatorname{Medical}(n=150)$} & \multicolumn{2}{|c|}{ Literature $(n=150)$} & & \\
\hline & & No & $\%$ & No & $\%$ & No & $\%$ \\
\hline \multirow{7}{*}{ Pain } & & & & & & & \\
\hline & 1 & 32 & 21.3 & 44 & 29.3 & 76 & 25.3 \\
\hline & 2 & 33 & 22.0 & 23 & 15.3 & 56 & 18.7 \\
\hline & 3 & 38 & 25.3 & 25 & 16.7 & 63 & 21.0 \\
\hline & 4 & 23 & 15.3 & 20 & 13.3 & 43 & 14.3 \\
\hline & 5 & 18 & 12.0 & 21 & 14.0 & 39 & 13.0 \\
\hline & 6 & 6 & 4.0 & 17 & 11.3 & 23 & 7.7 \\
\hline \multirow{7}{*}{ Anxiety } & & & & & & & \\
\hline & 1 & 31 & 20.7 & 31 & 20.7 & 62 & 20.7 \\
\hline & 2 & 43 & 28.7 & 30 & 20.0 & 73 & 24.3 \\
\hline & 3 & 36 & 24.0 & 19 & 12.7 & 55 & 18.3 \\
\hline & 4 & 18 & 12.0 & 22 & 14.7 & 40 & 13.3 \\
\hline & 5 & 15 & 10.0 & 22 & 14.7 & 37 & 12.3 \\
\hline & 6 & 7 & 4.7 & 26 & 17.3 & 33 & 11.0 \\
\hline \multicolumn{8}{|c|}{ Emotional Stress } \\
\hline $\mid$ & 1 & 23 & 15.3 & 20 & 13.3 & 43 & 14.3 \\
\hline & 2 & 30 & 20.0 & 17 & 11.3 & 47 & 15.7 \\
\hline & 3 & 34 & 22.7 & 21 & 14.0 & 55 & 18.3 \\
\hline & 4 & 21 & 14.0 & 25 & 16.7 & 46 & 15.3 \\
\hline & 5 & 27 & 18.0 & 17 & 11.3 & 44 & 14.7 \\
\hline & 6 & 15 & 10.0 & 50 & 33.3 & 65 & 21.7 \\
\hline \multirow[t]{7}{*}{$\begin{array}{l}\text { Mood i - } \\
\text { ness }\end{array}$} & & & & & & & \\
\hline & 1 & 31 & 20.7 & 20 & 13.3 & 51 & 17.0 \\
\hline & 2 & 32 & 21.3 & 10 & 6.7 & 42 & 14.0 \\
\hline & 3 & 36 & 24.0 & 24 & 16.0 & 60 & 20.0 \\
\hline & 4 & 23 & 15.3 & 17 & 11.3 & 40 & 13.3 \\
\hline & 5 & 11 & 7.3 & 16 & 10.7 & 27 & 9.0 \\
\hline & 6 & 17 & 11.3 & 63 & 42.0 & 80 & 26.7 \\
\hline \multirow{7}{*}{ Sadness } & & & & & & & \\
\hline & 1 & 22 & 14.7 & 35 & 23.3 & 57 & 19.0 \\
\hline & 2 & 32 & 21.3 & 19 & 12.7 & 51 & 17.0 \\
\hline & 3 & 32 & 21.3 & 21 & 14.0 & 53 & 17.7 \\
\hline & 4 & 33 & 22.0 & 19 & 12.7 & 52 & 17.3 \\
\hline & 5 & 13 & 8.7 & 21 & 14.0 & 34 & 11.3 \\
\hline & 6 & 18 & 12.0 & 35 & 23.3 & 53 & 17.7 \\
\hline \multicolumn{8}{|c|}{ Back and Joint Pain } \\
\hline & 1 & 35 & 23.3 & 24 & 16.0 & 59 & 19.7 \\
\hline & 2 & 32 & 21.3 & 16 & 10.7 & 48 & 16.0 \\
\hline & 3 & 26 & 17.3 & 28 & 18.7 & 54 & 18.0 \\
\hline
\end{tabular}




\begin{tabular}{|c|c|c|c|c|c|c|c|}
\hline & 4 & 19 & 12.7 & 18 & 12.0 & 37 & 12.3 \\
\hline & 5 & 25 & 16.7 & 19 & 12.7 & 44 & 14.7 \\
\hline & 6 & 13 & 8.7 & 45 & 30.0 & 58 & 19.3 \\
\hline \multicolumn{8}{|l|}{ Weight Gain } \\
\hline 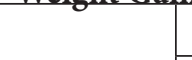 & 1 & 64 & 42.7 & 91 & 60.7 & 155 & 51.7 \\
\hline & 2 & 32 & 21.3 & 21 & 14.0 & 53 & 17.7 \\
\hline & 3 & 26 & 17.3 & 13 & 8.7 & 39 & 13.0 \\
\hline & 4 & 19 & 12.7 & 14 & 9.3 & 33 & 11.0 \\
\hline & 5 & 6 & 4.0 & 5 & 3.3 & 11 & 3.7 \\
\hline & 6 & 3 & 2.0 & 6 & 4.0 & 9 & 3.0 \\
\hline \multicolumn{8}{|l|}{ Heaviness } \\
\hline & 1 & 20 & 13.3 & 31 & 20.7 & 51 & 17.0 \\
\hline & 2 & 36 & 24.0 & 13 & 8.7 & 49 & 16.3 \\
\hline & 3 & 39 & 26.0 & 19 & 12.7 & 58 & 19.3 \\
\hline & 4 & 23 & 15.3 & 20 & 13.3 & 43 & 14.3 \\
\hline & 5 & 20 & 13.3 & 23 & 15.3 & 43 & 14.3 \\
\hline & 6 & 12 & 8.0 & 44 & 29.3 & 56 & 18.7 \\
\hline \multicolumn{8}{|l|}{ Swelling } \\
\hline & 1 & 81 & 54.0 & 77 & 51.3 & 158 & 52.7 \\
\hline & 2 & 34 & 22.7 & 22 & 14.7 & 56 & 18.7 \\
\hline & 3 & 13 & 8.7 & 10 & 6.7 & 23 & 7.7 \\
\hline & 4 & 9 & 6.0 & 15 & 10.0 & 24 & 8.0 \\
\hline & 5 & 9 & 6.0 & 12 & 8.0 & 21 & 7.0 \\
\hline & 6 & 4 & 2.7 & 14 & 9.3 & 18 & 6.0 \\
\hline \multicolumn{8}{|c|}{ Belly Swelling } \\
\hline & 1 & 41 & 27.3 & 42 & 28.0 & 83 & 27.7 \\
\hline & 2 & 26 & 17.3 & 13 & 8.7 & 39 & 13.0 \\
\hline & 3 & 37 & 24.7 & 15 & 10.0 & 52 & 17.3 \\
\hline & 4 & 20 & 13.3 & 26 & 17.3 & 46 & 15.3 \\
\hline & 5 & 15 & 10.0 & 18 & 12.0 & 33 & 11.0 \\
\hline & 6 & 11 & 7.3 & 36 & 24.0 & 47 & 15.7 \\
\hline
\end{tabular}

Table 2: Qualitative assessment of the severity of premenstrual symptoms 


\begin{tabular}{|c|c|c|c|c|c|c|}
\hline \multirow{3}{*}{ Functions } & \multicolumn{4}{|c|}{ School } & \multirow{2}{*}{\multicolumn{2}{|c|}{ Total $(n=300)$}} \\
\hline & \multicolumn{2}{|c|}{$\operatorname{Medical}(\mathrm{n}=150)$} & \multicolumn{2}{|c|}{ Literature $(n=150)$} & & \\
\hline & No & $\%$ & No & $\%$ & No & $\%$ \\
\hline \multicolumn{7}{|l|}{ Family Function } \\
\hline Unaffected / Slightly affected & 79 & 52.7 & 74 & 49.3 & 153 & 51.0 \\
\hline Moderately affected & 61 & 40.7 & 59 & 39.3 & 120 & 40.0 \\
\hline Significantly/Seriously affected & 10 & 6.7 & 17 & 11.3 & 27 & 9.0 \\
\hline \multicolumn{7}{|l|}{ Self-Care } \\
\hline Unaffected / Slightly affected & 85 & 56.7 & 74 & 49.3 & 159 & 53.0 \\
\hline Moderately affected & 53 & 35.3 & 51 & 34.0 & 104 & 34.7 \\
\hline Significantly/Seriously affected & 12 & 8.0 & 25 & 16.7 & 37 & 12.3 \\
\hline \multicolumn{7}{|l|}{ Concentration in class } \\
\hline Unaffected / Slightly affected & 77 & 51.3 & 58 & 38.7 & 135 & 45.0 \\
\hline Moderately affected & 56 & 37.3 & 49 & 32.7 & 105 & 35.0 \\
\hline Significantly/Seriously affected & 17 & 11.3 & 43 & 28.7 & 60 & 20.0 \\
\hline \multicolumn{7}{|l|}{ Exam Performance } \\
\hline Unaffected / Slightly affected & 104 & 69.3 & 66 & 44.0 & 170 & 56.7 \\
\hline Moderately affected & 34 & 22.7 & 41 & 27.3 & 75 & 25.0 \\
\hline Significantly/Seriously affected & 12 & 8.0 & 43 & 28.7 & 55 & 18.3 \\
\hline
\end{tabular}

Table 3: Effect of PMS severity on daily activities

\begin{tabular}{|c|c|c|c|c|c|c|}
\hline \multirow{3}{*}{$\begin{array}{l}\text { Assessment of dysmenorrhea se- } \\
\text { verity }\end{array}$} & \multicolumn{4}{|c|}{ School } & \multirow{2}{*}{\multicolumn{2}{|c|}{ Total $(n=300)$}} \\
\hline & \multicolumn{2}{|c|}{$\operatorname{Medical}(n=150)$} & \multicolumn{2}{|c|}{ Literature $(\mathrm{n}=150)$} & & \\
\hline & No & $\%$ & No & $\%$ & No & $\%$ \\
\hline Grade 0 & 26 & 17.3 & 12 & 8.0 & 38 & 12.7 \\
\hline Grade 1 & 66 & 44.0 & 51 & 34.0 & 117 & 39.0 \\
\hline Grade 2 & 51 & 34.0 & 76 & 50.7 & 127 & 42.3 \\
\hline Grade 3 & 7 & 4.7 & 11 & 7.3 & 18 & 6.0 \\
\hline
\end{tabular}

Table 4: Assessment of dysmenorrhea severity of the study participants

Similarly, the percentages in grades 2 and 3 category are higher in literature students than their medicine counterparts. On an average, grades 1 and 2 were more frequent than grades 0 and 3 (table 4). Short premenstrual assessment shows, as expected, that proportion of students with mild to moderate dysmenorrhea were in grades 0 and 1, whereas severe dysmenorrhea coincided with grades 2 and 3 (table S2). In the average population, grades 2 and 3 appear to be prevalent than grades 0 and 1 (figure 4B).

\section{Discussion}

Premenstrual syndrome is a collection of mood, behavior and physical changes that occur in women one to two weeks before menstruation and generally abates before the onset of menstrual flow. In most cases, these symptoms generate mild or moderate discomfiture that do not hinder daily activities to a large extent. However, some women undergo severe discomfort that affects their personal relationships, work and daily activities. PMDD is the severe form of PMS, that has been categorized as a "depressive disorder not otherwise specified" in DSM-IV (1). Diagnosis and management of PMS and PMDD relies on self-report of symptoms, their severity and impact on daily lives. 
Understanding of modifiable risk factors that affect these symptoms is therefore critical for effective control of PMS.

Till date, consistent and strong association between PMS and standard demographic risk factors such as education, income, employment, marital status, or number of children are lacking. Existing data are at times conflicting, necessitating well-designed studies to identify potential demographic risk factors. For example, menstrual cycle characteristics such as cycle length or age at menarche are not associated with PMS. Similarly, oral contraceptive use is also not considered a risk factor for PMS.

In this study, we analyzed several socio-demographic, gynecological and lifestyle related parameters as possible risk factors or predictors of PMS among college students of Taibah University, Saudi Arabia. We also compared the prevalence and severity of PMS between two groups of students-those studying medicine and literature, and attempted to correlate it with their responses to the risk factor questionnaires. Similar studies have been conducted in other countries [24]. However, Saudi Arabia has a unique cultural identity, where notions of * syndromes ${ }^{\star}$ or ${ }^{*}$ diseases $^{\star}$ are often self-defined or neglected. Hence, there is an utmost need to identify modifiable PMS risk factors early on in a woman's life in Saudi society to ensure timely and correct PMS management and a normal lifestyle. Results obtained from questionnaires completed by students who have not been chosen randomly (voluntary participation), which could imply a selection bias. However, when comparing both populations it can be assumed that such bias could be similar in both.

We find that medical students suffer less from PMS than literature students $(\mathrm{p}=0.002$, table $\mathrm{S} 1)$. Their responses to the degree of discomfiture experienced in both psychological and somatic aspects of PMS are on a lower grade than their literature counterparts. The latter experience more severe symptoms and are highly affected in their routine chores, academic performance and self-care. Similar reports are available across the globe. For example, Tadakawa et al. report that one in nine girls in Japanese high schools of Sendai province were absent from school due to PMS [25]. We speculate that the reason for this observation could be better PMS awareness and related education in the medical discipline than in humanities. In fact Dennerstein et al. report that education, indeed, plays an important role in understanding and handling PMS [26]. The percentages that had mild to moderate PMS were comparable between the two (table S1). Marital status and family history of PMS are also relevant predictors for developing PMS. Isik et al. document contribution of family history towards developing PMS in a study of
Turkish health students [27]. Nisar et al. also report a significant association of family history with PMS among students of Sindh, Pakistan [28]. Rasheed et al. found a relation between maternal family history of PMS and propensity of developing PMS in their study respondents [29]. We report that single women $(p=0.001$, table S1) and women with family history of PMS ( $\mathrm{p}=0.003$, table S1) tend to experience PMS more frequently than married women or those with no family history.

We also observe that medical students exercise better than literature students. Although there is no discernible pattern connecting PMS severity with amount of exercise in the average population of students, it is possible that medical students specifically are fitter than those studying literature, and hence have less severe PMS. There are several reports elucidating the positive effect of yoga and aerobics on PMS in Taiwanese and Iranian females respectively $[30,31]$. Studies on reproductive hormones, ovarian cyclicity and menstrual patterns of female athletes also indicate that exercise has a beneficial effect on controlling PMS $[32,33]$. Thus, exercise is an important lifestyle-related risk factor that can be regulated to achieve comfortable premenstrual days.

There are conflicting reports about effect of diet on PMS. Some studies report diet to significantly influence PMS. A cross-sectional study of Japanese high school girls shows a preference for salty foods and lack of exercise as potential risk factors for PMS [25]. A survey among university students of Dammam, Saudi Arabia, demonstrates a positive link between sugary diet and PMS [29]. Oral et al. obtained similar results in their study on Turkish medical students [21]. A Turkish survey claims that irregular breakfast predisposed health science students to PMS [27]. According to Farasati et al., a Western style diet and a diet rich in sugars predisposes one to severe PMS [34]. Rossignol et al. found that consumption of chocolate and alcohol coincides with severity of PMS symptoms [35]. Conversely, administration of omega-3 fatty acids reduces the severity of PMS considerably [36]. A detailed study by Bianco et al. reveals that lower intake of complex carbohydrates, fibres, calcium, vitamin B6, coupled with higher intake of simple sugars, sodium, caffeine leads to severe PMS [37]. On the other hand, Gold et al. reports that dietary factors had no effect on PMS symptoms in their cross-sectional study [38]. We do not see any clear dependence of PMS on diet type in the average population. However, we do observe severe PMS in a higher percentage of students who had irregular meals or carbohydrate-rich food compared to those who consumed regular balanced meals. The effect of caffeine on PMS is controversial. Purdue-Smith et al. found that caffeine intake had 
no influence on PMS severity [39], whereas Bianco et al. report that caffeine consumption, among other nutritional parameters, contributed to $27 \%$ of non-cyclical PMS [37]. We find no relation between caffeine consumption and PMS in our respondents.

A strong positive relationship between BMI and the risk of developing PMS was observed in a recent study, with an increase of $3 \%$ in PMS risk linked to $1 \mathrm{~kg} / \mathrm{m}^{2}$ rise in BMI [40]. Conversely, a survey of lifestyle parameters of Turkish health science students shows that low BMI is a risk factor for PMS [41]. In short, BMI affects PMS severity if it is either too high or low. However, we fail to see any connection between BMI and PMS in our respondents in general. Nonetheless, we note that the numbers of literature students with $\mathrm{BMI} \geq 30$ are more than double the figures of medical ones. This could be again an indication of a lifestyle risk factor predictive of PMS.

Smoking is another risk factor for PMS that has been identified by various studies across the world. Dennerstein et al. and Bianco et al. associate smoking as a modifiable risk factor in studies on Australian and Italian women respectively [26, 38]. Sakai et al. found a correlation between light smoking habit and severe premenstrual phenomenology in young Japanese women. They also report that frequency and craving for smoking increases during the late luteal phase $[42,43]$. Interestingly, we do not perceive any correlation between smoking and PMS severity. However, there is an increase in the percentage suffering from moderate PMS in the smoking cessation category, probably implying that a withdrawal effect coincides with the premenstrual phase.

We assessed the correlation of PMS with dysmenorrhea among our study participants. Though these two phenomena occur at different time points in a woman's menstrual cycle, correlation between them exists $[21,22]$. In other words, women who experience PMS may also have dysmenorrhea. A study of symptom trajectories of PMS and dysmenorrhea for 13 years in Australian women reports that $80 \%$ of the women had PMS and $60 \%$ had dysmenorrhea [44]. A study conducted among college students of Isra University of Sindh, Pakistan, found a correlation between dysmenorrhea and PMS [28]. We find that participants who reported severe PMS also suffered from dysmenorrhea ( $\mathrm{p}=$ 0.000 ). Furthermore, the mean of SPAF of our participants was higher in grades 2 and 3 of dysmenorrhea.

\section{Conclusion}

This is the first comparative study of premenstrual syndrome, and its prevalence, severity and risk factors among students of medicine and literature in Saudi Arabia. Different dis- ciplines of study entail differences in lifestyle parameters such as diet, exercise, caffeine intake and smoking that may affect PMS. Additionally, there are factors such as marital status, family history of PMS and dysmenorrhea that affect PMS. We find marital status, family history of PMS, dysmenorrhea and diet to be modifiable risk factors for our participants. Awareness and education about PMS and its risk factors should be considered for effective management of the syndrome and enhancement of the quality of daily life among Saudi women.

\section{References}

1. Braverman PK. (2007) Premenstrual syndrome and premenstrual dysphoricdisorder. J. Pediatr. Adolesc. Gynecol. $1: 3-12$

2. O’Brien PM, Eriksson E. (2008) Premenstrual syndrome. Lancet. 371:1200-10.

3. Silva CM, Gigante DP, Carret ML, Fassa AG. (2006) Population study of premenstrual syndrome. Rev Saude Publica. 40:47-56.

4. American Psychiatric Association. (1994) Diagnostic and Statistical Manual of Mental Disorders, fourth edition (DSM-IV).

5. World Health Organization (WHO). (1992) International Statistical Classification of Diseases and Related Health Problems. 10thRevision (ICD -10). Geneva: WHO.

6. Premenstrual syndrome (PMS) fact sheet. (2014) Office on Women's Health.

7. Biggs WS, Demuth, RH. (2011) Premenstrual syndrome and premenstrual dysphoric disorder. American family physician. 8:918-24.

8. Merck Manual Professional - Menstrual Abnormalities. (2005).

9. Johnson S, PHD. Premenstrual Syndrome (Premenstrual Tension) Menstrual Abnormalities and Abnormal Uterine Bleeding. Armenian Health Network, Health, am.

10. Dickerson, Lori M.; Mazyck, Pamela J.; Hunter, Melissa H. (2003) Premenstrual Syndrome. American Family Physician. $8: 1743-52$.

11. Harlow SD, Park M: (1996) A longitudinal study of risk factors for the occurrence, duration and severity of menstrual cramps in a cohort of college women. Br. J. Obstet. Gynaecol. 103:1134-1142.

12. Rivera-Tovar AD, Frank E. (1990) Late luteal phase dysphoricdisorder in young women. Am. J. Psychiatry 147:1634

13. Adewuya AO, Loto OM, Adewumi TA. (2008) Premen- 
strual dysphoric disorder amongst Nigerian university students: Prevalence, co-morbid conditions, and correlates. Arch. Womens Ment. Health. 11:13-8.

14. Steiner M, Macdougall M, Brown E. (2003) The premenstrual symptoms screening tool (PSST) for clinicians. Arch. Womens Ment. Health 6:203-9.

15. Wittchen HU, Becker E, Lieb R, Krause P. (2002) Prevalence, incidence and stability of premenstrual dysphoric disorder in the community. Psychol. Med. 32:119-32

16. Akabat, Mohammed Y. (2012) Menstrual disorders in female medical students in Thamar University. Middle East Journal of Family Medicine. 2:32-36.

17. Mahesh A, Tirmizi SZA, Ali SS. (2011) Frequency and associated factors of premenstrual syndrome in medical college girls. Medical Channel 1:2011-34.

18. Seedhom AE, Mohammed ES, Mahfouz EM. (2013) Life Style Factors Associated with Premenstrual Syndrome among El-Minia University Students, Egypt. ISRN Public Health ID 617123,6 .

19. Issa BA, Yussuf AD, Olatinwo AW, Ighodalo M. (2010) Premenstrual dysphoric disorder among medical students of a Nigerian university. Annals of African medicine year: 3:118-122.

20. Tolossa FW, Bekele ML. (2014) Prevalence, impacts and medical managements of premenstrual syndrome among female students: cross-sectional study in College of Health Sciences, Mekelle University, Mekelle, northern Ethiopia. BMC Women's Health. 14-52.

21. 21.Oral E, Kirkan ES, Yazici E, Gulec M, Cansever Z, Aydin N. (2012) Premenstrual symptom severity, dysmenorrhea, and school performance in medical students. J. Mood Disorders. $4: 143-152$.

22. Shrotriya C, Ray A, Ray S, Thomas GA. (2012) 'Menstrual characteristics' and 'prevalence and effects of dysmenorrhea' on quality of life of medical students. International Journal of Collaborative Research on Internal Medicine \& Public Health 4.

23. Balaha MH, Amr MA, Saleh Al Moghannum M, Saab Al Muhaidab N. (2010) The phenomenology of premenstrual syndrome in female medical students: a cross sectional study. Pan Afr. Med. J. 5:4.

24. Andersch B, Milsom I. (1982) An epidemiologic study of young women with dysmenorrhea. Am. J. Obstet. Gynecol. 6:655-60.

25. Tadakawa M, Takeda T, Monma Y, Koga S, Yaegashi N. (2016) The prevalence and risk factors of school absenteeism due to premenstrual disorders in Japanese high school students-a school-based cross-sectional study. Biopsychosoc. Med. 10:13.
26. Dennerstein L, Lehert P, Heinemann K. (2011) Global study of women's experiences of premenstrual symptoms and their effects on daily life. Menopause Int. 3:88-95.

27. İşik H, Ergöl Ş, Aynioğlu Ö, Şahbaz A, Kuzu A, Uzun M. (2016) Premenstrual syndrome and life quality in Turkish health science students. Turk. J. Med. Sci. 3:695-701.

28. Nisar N, Zehra N, Haider G, Munir AA, Sohoo NA. (2008) Frequency, intensity and impact of premenstrual syndrome in medical students. J. Coll. Physicians Surg. Pak. 8:481-4.

29. Rasheed P, Al-Sowielem LS. (2003) Prevalence and predictors of premenstrual syndrome among college-aged women in Saudi Arabia. Ann. Saudi Med. 6:381-7.

30. Tsai SY (2016) Effect of Yoga Exercise on Premenstrual Symptoms among Female Employees in Taiwan. Int. J. Environ. Res. Public Health. 13.

31. Samadi Z, Taghian F, Valiani M. (2013) The effects of 8 weeks of regular aerobic exercise on the symptoms of premenstrual syndrome in non-athlete girls. Iran J Nurs Midwifery Res. $1: 14-9$.

32. Czajkowska M, Drosdzol-Cop A, Gałązka I, Naworska B, Skrzypulec-Plinta V. (2015) Menstrual Cycle and the Prevalence of Premenstrual Syndrome /Premenstrual Dysphoric Disorder in Adolescent Athletes. J. Pediatr. Adolesc. Gynecol. 6:4928 .

33. Orio F, Muscogiuri G, Ascione A, Marciano F, Volpe A, La Sala G, et.al. (2013) Effects of physical exercise on the female reproductive system. Minerva Endocrinol. 3:305-19.

34. Farasati N, Siassi F, Koohdani F, Qorbani M, Abashzadeh K, Sotoudeh G. (2015) Western dietary pattern is related to premenstrual syndrome: a case-control study. Br. J. Nutr. 12-21.

35. Rossignol AM, Bonnlander H. (1991) Prevalence and severity of the premenstrual syndrome. Effects of foods and beverages that are sweet or high in sugar content. J. Reprod. Med. 2:131-6.

36. Sohrabi N, Kashanian M, Ghafoori SS, Malakouti SK. (2013) Evaluation of the effect of omega-3 fatty acids in the treatment of premenstrual syndrome: "a pilot trial". Complement Ther Med. 3:141-6.

37. Bianco V, Cestari AM, Casati D, Cipriani S, Radici G, Valente I. (2014) Premenstrual syndrome and beyond: lifestyle, nutrition, and personal facts. Minerva Ginecol. 4:365-75.

38. Gold EB, Bair Y, Block G, Greendale GA, Harlow SD, Johnson S, et.al. (2007) Diet and lifestyle factors associated with premenstrual symptoms in a racially diverse community sample: Study of Women's Health Across the Nation (SWAN). J. Womens Health (Larchmt). 5:641-56. 
39. Purdue-Smithe AC, Manson JE, Hankinson SE, Bertone-Johnson ER. (2016) A prospective study of caffeine and coffee intake and premenstrual syndrome. Am. J. Clin. Nutr. 2:499507.

40. Bertone-Johnson ER, Hankinson SE, Willett WC, Johnson SR, Manson JE. (2010) Adiposity and the development of premenstrual syndrome. J. Women's Health (Larchmt). 11:195562.

41. Kahvaoglu Sut H, Mestogullari E. (2016) Effect of Premenstrual Syndrome on Work-Related Quality of Life in Turkish Nurses. Saf Health Work. 1:78-82.

42. Sakai H, Obashi K. (2013) Association of menstrual phase with smoking behavior, mood and menstrual phase-associated symptoms among young Japanese women smokers. BMC Womens Health. 13-10.

43. Sakai H, Kawamura C, Cardenas X, Obashi K. (2011) Premenstrual and menstrual symptomatology in young adult Japanese females who smoke tobacco. J. Obstet. Gynaecol. Res. 4:325-30.

44. Ju H, Jones M, Mishra GD. (2014) Premenstrual syndrome and dysmenorrhea: symptom trajectories over 13 years in young adults. Maturitas 2:99-105.

45. Geeta Shamnani. (2018) Prevalence of premenstrual syndrome and premenstrual dysphoric disorder among medical students and its impact on their academic and social performance. National Journal of Physiology, Pharmacy and Pharmacology 8-8.
Submit your manuscript to a JScholar journal and benefit from:

ब Convenient online submission

- Rigorous peer review

I Immediate publication on acceptance

q Open access: articles freely available online

I High visibility within the field

- Better discount for your subsequent articles

Submit your manuscript at http://www.jscholaronline.org/submit-manuscript.php 